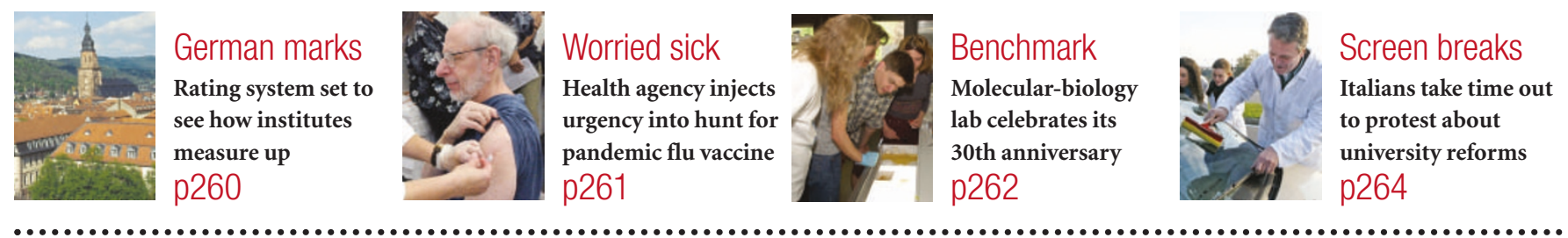

\title{
Campaign to fight malaria hit by surge in demand for medicine
}

\section{David Cyranoski, Tokyo}

An alarming shortfall of a key drug is undermining an international drive to reduce the malaria death toll. A rise in demand has led to a shortage of artemisinin, the main treatment for malaria that is resistant to conventional therapies, the World Health Organization (WHO) announced on 8 November.

Artemisinin is extracted from the wormwood plant, Artemisia annua, which grows wild in southern China and Vietnam. Combined with other drugs, its derivatives, such as artesunate and artemether, can clear symptoms of malaria in three days. Malaria currently kills about a million people every year, mainly in Africa.

In 2001, the WHO recommended that artemisinin-based combination therapies, or ACTs, should be used in countries where there is resistance to drugs such as chloroquine. Artemisininbased drugs are more expensive than conventional treatments, in part because large doses are required.

The WHO reached a high-profile agreement with drug firm Novartis in 2001 for the company to supply one such ACT - artemether-lumefantrine (Coartem) - at cost price. In May this year, the Geneva-based Global Fund to Fight AIDS, Tuberculosis and Malaria took the further step of requiring all of its malaria grants to be used on artemisininbased drugs.

\section{Production problems}

Forty countries have started using ACTs, 18 of them since January. Requests for Coartem treatment courses alone are projected to rise to 10 million in 2004 - up from 220,000 in 2001 — and to hit 60 million next year.

The challenge of meeting this increasing demand took a turn for the worse in July, when the major supplier of artemether, Kunming Pharmaceutical of Yunnan, China, said it could not keep up. In October, the WHO learned that Novartis would not be able to deliver much more than half of the 4.5 million doses it requested by March 2005.

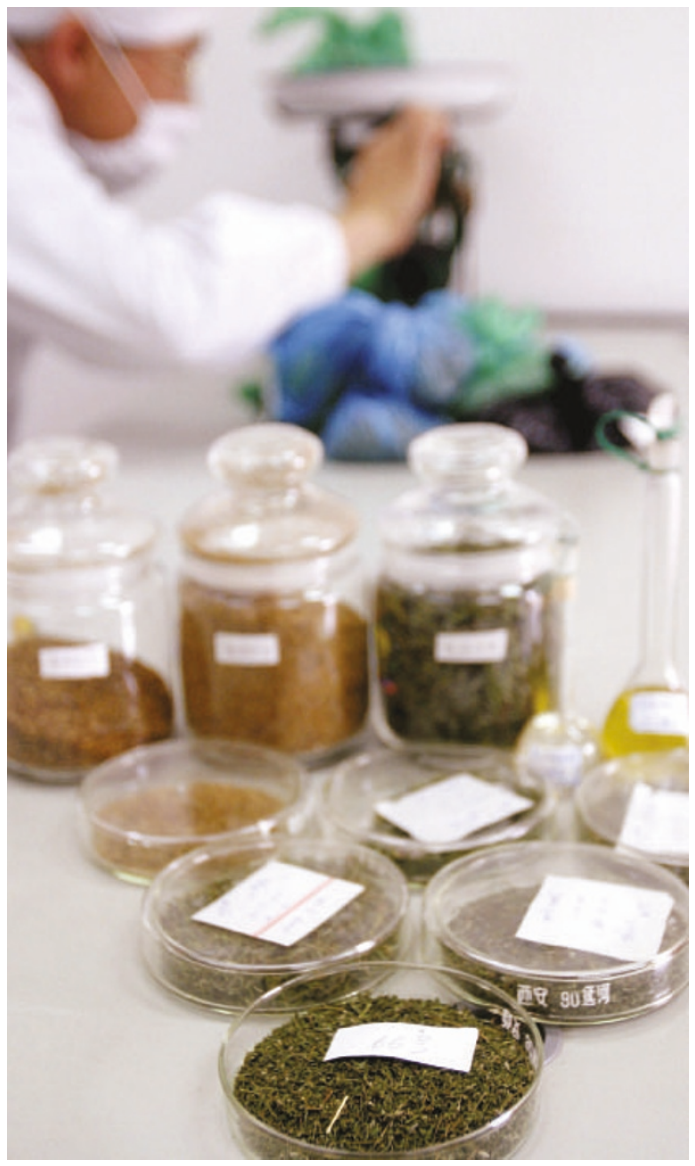

Natural high: demand for products of the wormwood plant, which is used to make antimalarial drugs, has soared.

"We were shocked - nobody thought the situation would be this bad," says Andrea Bosman, medical officer for the WHO's Roll Back Malaria campaign. Bosman says she is expecting about 2.4 million doses from Novartis in this period. "Are other companies better off? Probably not."

Countries such as Ethiopa, where up to 70,000 people died from malaria last year, will be hit particularly hard. It will only receive about half of the two million doses that its government has requested.

Cultivation and extraction take a minimum of nine months, and $\mathrm{Li} \mathrm{Su}$, a spokeswoman for Kunming Pharmaceutical, says the company was not given enough notice to prepare. "Before June 2004, we never got a guarantee of a large order from Novartis," she says. The company is now ramping up production. A factory that can produce 20 tonnes of artemether a year — the full amount requested by Novartis — is due to open next autumn.

But manufacturing capacity only matters if the raw material is available. Increasing demand has pushed up the price and forced producers to use lowquality, low-yield leaves. Kunming Pharmaceutical will open its own plantation in February.

With production looking bleak for months to come, Bosman says that one of the greatest concerns is the further spread of ineffective fake ACTs. "This will feed a huge black market," she says.

Work is also under way to find varieties that grow well in local climates in Africa. Tanzania already has a promising variety and should be able to provide 20 tonnes by 2006, says Bosman.

\section{Chemical fix}

Long-term, hopes are resting on the development of synthetic artemisininbased drugs, which avoid the unreliability of cultivation. Scientists at the University of California, Berkeley, have created transgenic bacteria that can make a precursor to artemisinin. (V. J. J. Martin et al. Nature Biotechnol. 21, $796-802 ; 2003)$. They are now trying to make bacteria that can recreate the entire artemisinin synthetic pathway, aiming for industrial production by 2009. They say this would slash the price to one-tenth of its current level.

Another synthetic solution may be closer to hand.A chemically synthesized compound called RBx-11160, which mimics the chemical and biological properties of artemisinin (J.L. Vennerstrom et al. Nature 430, 900-904; 2004), is already in clinical trials in Britain.

Novartis says it remains optimistic of getting back on track. But the WHO, after years of trying to persuade countries to use ACTs, has been forced to recommend that they use quinine until stocks recover. 